\title{
Individual differences in working memory capacity and enumeration
}

\author{
STEPHEN W. TUHOLSKI \\ Southern Illinois University, Edwardsville, Illinois \\ RANDALL W. ENGLE \\ Georgia Institute of Technology, Atlanta, Georgia \\ and \\ GORDON C. BAYLIS \\ University of South Carolina, Columbia, South Carolina
}

\begin{abstract}
Two experiments are reported in which subjects performed working memory and enumeration tasks. In the first experiment, subjects scoring low on the working memory task also performed poorly on the attention-demanding "counting" portion of the enumeration task. Yet no span differences were found for the non-attention-demanding "subitizing" portion. In Experiment 2, conjunctive and disjunctive distractors were added to the enumeration task. Although both high and low working memory span subjects were adversely affected by the addition of conjunctive distractors, the effect was much greater for the low-span subjects. Implications from these findings are that differences in working memory capacity correspond to differences in capability for controlled attention.
\end{abstract}

Since the pioneering work of Baddeley and his colleagues (e.g., Baddeley, 1986; Baddeley \& Hitch, 1974) several theories of working memory differing in scope and level of analysis (see Miyake \& Shah, 1999, for reviews) have been proposed. Despite the numerous theoretical perspectives and research paradigms implemented in working memory research, there is general agreement that working memory is used when the task at hand demands the concomitant processing and storage of information, and that the capacity to perform these operations is limited. Given the impressive relationship between working memory capacity and real-world cognitive skills such as reading comprehension(Daneman \& Carpenter, 1980), language comprehension (King \& Just, 1991; MacDonald, Just, \& Carpenter, 1992), and reasoning ability (Kyllonen \& Chrystal, 1990), a better understanding of working memory capacity limitations will provide a better understanding of the limits of cognitive ability. Although there is some support for the notion that skills and experience can be utilized to override the inherent capacity limitations of working memory (Ericsson \& Dulaney, 1999; Ericsson \& Kintsch, 1995; Miyake \& Shah, 1999), our concern in the present study lies with identifying the mechanism responsible for basic capacity limitations of working memory.

We thank Gordon Logan, Michael Kane, and an anonymous reviewer for their helpful comments on earlier versions of this manuscript. Correspondence should be sent to S. W. Tuholski, Department of Psychology, Southern Illinois University, Edwardsville, IL 62026 (e-mail: stuhols@siue.edu).
Our contention is that working memory capacity is limited by one's capability to use controlled processing (Engle, Kane, \& Tuholski, 1999). Controlled processing is important when information in memory must become or remain activated, particularly when distracting information competes for attention. Thus controlled processing involves the processes of activating and maintaining goalor task-relevant information, as well as that of actively inhibiting information that competes for attention and is irrelevant to the goal or task at hand. People who differ in their level of working memory capacity should differ only when attention must be controlled; differences should not arise when a task can be performed with automatic processing.

A number of studies demonstrate that subjects with high working memory capacity perform better than those with low working memory capacity on interferencesensitive tests. In comparison with low working memory capacity subjects, high-capacity subjects recall more category exemplars in a verbal fluency task, particularly when recall intervals are long and retroactive interference is greatest (Rosen \& Engle, 1997); produce less "fan" interference under interference conditions (Conway \& Engle, 1994); produce more negative priming (Conway, Tuholski, Shisler, \& Engle, 1999); and show less proactive interference (Kane \& Engle, 2000; Rosen \& Engle, 1998). Interestingly, in each case in which interference has been reduced or resistance to interference has been made difficult because a secondary load has been imposed, the difference between high- and lowcapacity subjects has disappeared. Moreover, it has al- 
ways been the case that, under load, the high-capacity subjects regress to the performance of the low-capacity subjects. For example, the difference between high- and low-capacity subjects has been eliminated in the verbal fluency and negative priming paradigms when concurrent tasks are performed (Conway et al., 1999; Rosen \& Engle, 1997). Also, differences in "fan" interference have been eliminated when the study materials contain less interference (Conway \& Engle, 1994). These studies converge on the notion that individual differences in working memory capacity result in individual differences in tasks that demand controlled processing, particularly when the ability to handle interfering information is at a premium. When high-capacity subjects can no longer use their superior controlled processing capacity or the task no longer demands it, their performance is indistinguishable from that of low-capacity subjects.

\section{Present Experiments and Hypotheses}

The goal of the present study is to add to the existing evidence of a working memory-controlled processing relationship and extend it further by demonstrating that subjects differing in working memory capacity will differ only on a task that requires controlled processing. To do so, we used an enumeration task that has been studied nearly as long as experimental psychology has existed (e.g., Jevons, 1871), but that has been used more recently by Trick \& Pylyshyn $(1993,1994)$. In the task, subjects are presented with $n$ objects to count. When $n$ is from one to four, there is typically a very small increase in reaction time as $n$ increases. The enumeration of one to four objects is presumed to occur through a process called subitizing, which is thought to be an automatic process, used for pattern recognition. When $n$ is greater than four, the slope of enumeration time as a function of $n$ is much steeper. On these trials, subjects are presumed to invoke a controlled counting process. Whereas a subitizing slope is typically $40-80 \mathrm{msec}$ per object, a counting slope is typically $300-400 \mathrm{msec}$ per object (Trick \& Pylyshyn, 1994). Thus, the relatively simple task of counting objects provides an opportunity for studying individual differences on automatic and controlled processing trials.

Pylyshyn (1994; Trick \& Pylyshyn, 1994) have offered the most elegant account of the difference between subitizing and controlled counting. According to their theory, subitizing is a by-product of the way in which the visual system normally operates in its preattentive stage. When subjects are presented with more items than can be processed in this preattentive stage, controlled counting processes are invoked. According to Trick and Pylyshyn (1994), controlled counting involves a number of stages, including keeping track of where the focus of attention has visited, as well as planning where to move attention next. Further, inhibition of previously viewed locations, by not allowing subjects to "re-count" previously counted items, may also play an important role in subjects' counting efficiency in these conditions. By definition, then, increasingly large displays are laden with increasingly more interference, as it becomes more difficult to keep track of where attention has been, and where it should be moved next. Not surprisingly, error rates are typically larger for enumeration trials that are beyond the subitizing range (Trick \& Pylyshyn, 1994).

What can this task tell us about the capacity limitations of working memory? Given the attention-demanding aspects of the counting trials of an enumeration task, simply that subjects with less working memory capacity should have steeper reaction time slopes on the counting trials of the enumeration task than should subjects with more working memory capacity. Moreover, because subitizing is a process that requires very little controlled processing, the two group's reaction time slopes should not differ on the subitizing portion of the enumeration task.

\section{EXPERIMENT 1}

\section{Method}

Subjects. All subjects $(N=30)$ were undergraduates recruited from the University of South Carolina Psychology Department Human Subject Pool who participated in return for course credit. Each subject performed the enumeration task and the Operation Span (OSPAN) task developed by Turner and Engle (1989). The OSPAN task is a span test of working memory capacity that is a valid and reliable test of working memory capacity (Engle, Tuholski, Laughlin, \& Conway, 1999) requiring the concomitant processing and storage of information.

Apparatus. The enumeration and OSPAN tasks were controlled by Micro Experimental Laboratory (MEL) Version 2.0. The OSPAN task was run on an IBM PS/2 Model 70 computer with a VGA monitor. The enumeration task was run on an Inteva 586 computer with a Dell VGA monitor. The MEL Response Box Version 2.0 collected vocal responses in the enumeration task. Subjects performed the OSPAN task on 1 day and returned, typically within 3 weeks, to perform the enumeration task.

OSPAN. Arithmetic problems and unrelated words (e.g., Is $(4 \times$ $2)+1=11$ ? DOG) were presented one at a time, centered on a computer screen. The math problem and word presentations are referred to as a "math/word presentation." Subjects were instructed to read the math problem aloud, indicate whether the given answer was correct, and then read aloud the unrelated word. Thus, in the previous example, the subject should say "Is four times two plus one equal to eleven, no, dog." Immediately after the subject said the unrelated word, the experimenter pressed a key that made either another math/ word presentation or a recall cue (a string of three question marks) appear. When the recall cue appeared, the subjects were told to write down as many words as they could remember, in the order in which they appeared. The number of math/word presentations given before a recall cue appeared varied from two to six in the same random order for each subject. Before beginning the critical trials, the subjects were given three practice trials that included two math/word presentations. The OSPAN score was the total number of words recalled from only the trials in which all words were recalled in their correct order. For example, if a subject was presented with

$$
\begin{aligned}
& \text { IS }(8+2) / 5=2 ? \text { HOUSE } \\
& \text { IS }(9-3) \times 4=12 ? \text { CHAIR } \\
& \text { IS }(4+3) \times 2=14 ? \text { DOG }
\end{aligned}
$$

he/she was given credit for three words if he/she recalled HOUSE, CHAIR, DOG. The subject would not receive credit if the recall was incomplete (e.g., HOUSE, CHAIR) or in the incorrect serial order (e.g., CHAIR, DOG, HOUSE)

Enumeration. The subjects were tested in a dark room with the only light being from the monitor. On each trial, 1-12 yellow ver- 
tical bars measuring $1 \times 10$ pixels were presented on the computer screen. The background color was set to black. The subjects were instructed to silently count the bars as quickly as possible without sacrificing accuracy. When the subjects knew how many bars appeared on the screen, they indicated the number by saying the number into a hand-held microphone. The bars appeared in any of 42 locations demarcated by a $6 \times 7$ matrix (not visible to the subject) of possible target locations, which covered an area of approximately $4.0^{\circ} \times 6.0^{\circ}$ of visual angle. Before each trial, a ready signal $(*)$ appeared in the center of the target matrix for $500 \mathrm{msec}$, followed by a blank screen for $50 \mathrm{msec}$ and then the enumeration display, which remained on the screen until the subject responded aloud with the number of bars.

The oral response activated a speech trigger in a MEL Serial Response Box microphone Model 200a. Time was recorded from the onset of the enumeration display until the oral response. Immediately following the response, the experimenter keyed in the response to record accuracy. Twenty trials of each target display size were presented, resulting in 240 experimental trials per subject. Each subject was presented with a different random order of trials. The trials were presented in four 60-trial blocks, and subjects were allowed to rest between blocks. Any trial in which a subject made an incorrect response or in which the microphone malfunctioned was run again at the end of the block. This resulted in 20 correct responses for each target display size for each subject. The subjects were given 12 practice trials before starting the task. Throughout the rest of this paper, display size will be used to refer to the number of targets presented on a given trial, and display type will be used to refer to whether the trial was a subitizing (display size 1-3) or counting (display size 5-12) trial.

\section{Results and Discussion}

High-span subjects' $(n=15)$ mean OSPAN score was $22.98(S D=5.76)$. Low-span subjects' $(n=15)$ mean OSPAN score was $7.48(S D=2.15)$.
Because we were interested in the time to perform the enumeration task, and because the only effect in the accuracy data was the main effect of display type, only reaction time data will be reported. It should be noted that there were no effects of working memory span in the error data, and in fact, the accuracy rates were very high for both high-span (95.2\%) and low-span (97.2\%) subjects. Such high accuracy rates indicated that subjects followed the instructions to perform as quickly as possible without sacrificing accuracy. This also means, however, that we could not use number of errors to make inferences about group differences in counting time.

Before proceeding with the analysis of reaction time slopes, we present the data in its original, nonderived form. This analysis reaches the same conclusion as do the slope analyses, but it is presented here to demonstrate the magnitude of the reaction time effects, as well as to demonstrate that the effects are linear, and that slope derivations are warranted. Means of block median reaction times were submitted to a span (high, low) by number of objects (1-12) mixed analysis of variance. As expected, there was an interaction between span and display type $[F(11,308)=$ $\left.7.65, M S_{\mathrm{e}}=194,237, p<.01\right]$. As can be seen in Figure 1 , the interaction occurred because of virtually no difference in reaction time between high and low spans when 1-4 objects were presented; the reaction times diverge greatly thereafter. In fact, when subjects were presented with 12 lines to count, there is nearly a 700-msec difference between the high- and low-span subjects' reaction times. Clearly, the difference between high- and low-span subjects occurs over the attention-demanding

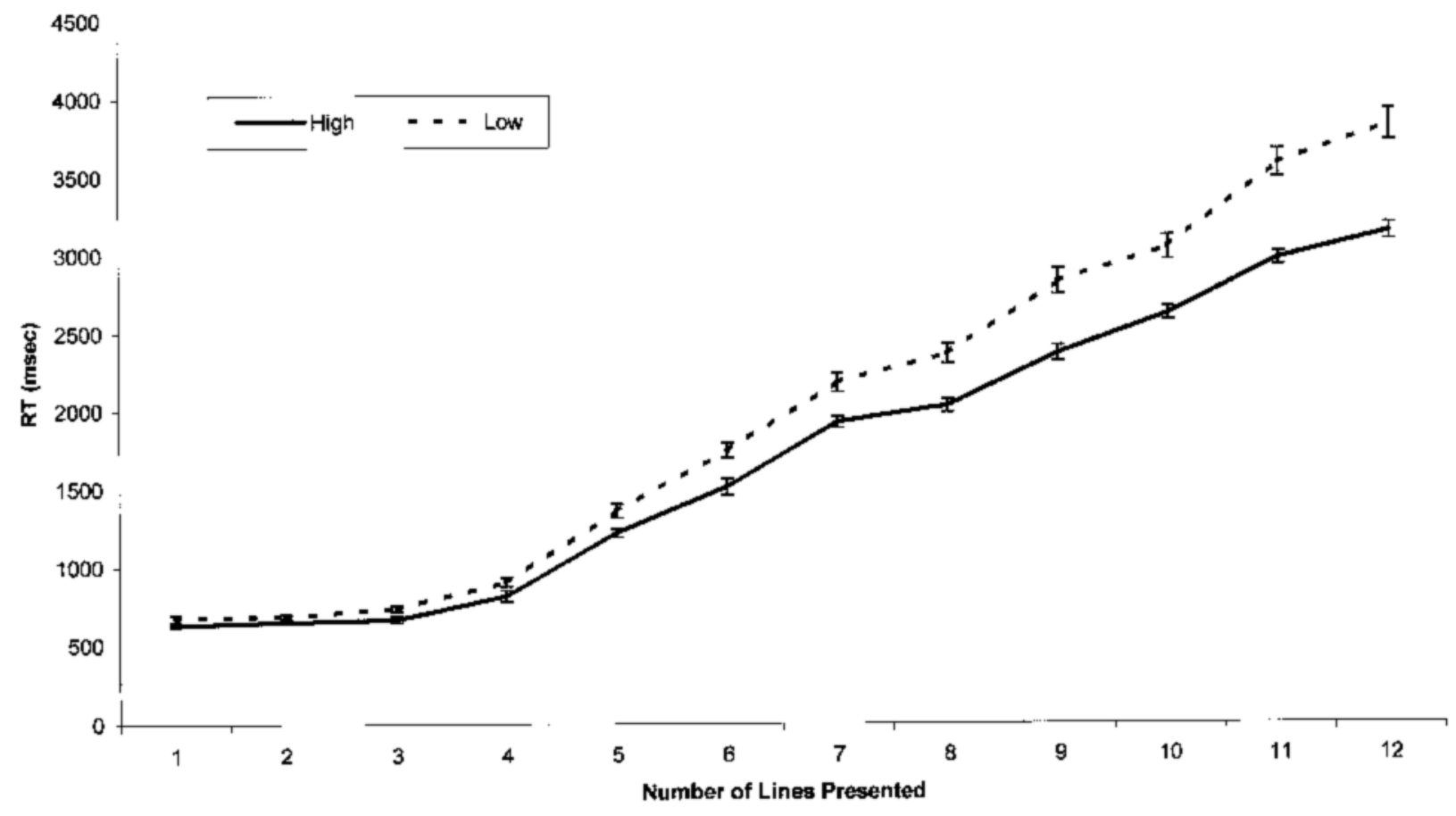

Figure 1. Differences in reaction time between high and low spans as a function of number of objects displayed, Experiment 1. 
counting range, and not at the subitizing range. Because the "raw" data from both experiments were consistent with an assumption of linearity, we will present only the slope data for the remaining analyses.

Before we calculated subitizing and counting slopes, subitizing spans were computed for each subject, using a method, first described by Chi and Klahr (1975), that has been used extensively in enumeration studies (Trick \& Pylyshyn, 1994). Because individual differences in subitizing span are documented (Trick \& Pylyshyn, 1994), this analysis was done at the level of the subject. To calculate subitizing spans, a series of incremental analyses that tested linear and quadratic trends were performed on each subject's enumeration data, beginning with target display sizes 1-3, then 1-4, and so forth. The subitizing span for the subject was indicated when the quadratic trend became significant. That is, if the quadratic trend was significant over the target display size $1-4$, but not 1-3 range, that would indicate that the subject was able to subitize three bars, but not four. Interestingly, there were no differences between high- and low-span subjects with regard to subitizing span size. The average subitizing span was $3.35(S D=.67)$ and $3.25(S D=.81)$ for high- and low-span subjects, respectively.

After we determined the subitizing span for each subject, counting and subitizing slopes were estimated for each subject, using the REG procedure in SAS (SAS Institute, Version 6.11). This was accomplished by fitting a regression model that predicted reaction time by the number of bars that were presented to a subject on each trial. Subitizing slopes were estimated in this way by examin- ing trials that had one to three bars, while counting slopes were estimated by examining trials that had 5 to 12 bars. The split-half reliability for subitizing and counting slopes was .89 and .95 , respectively.

Not surprisingly, counting slopes were greater than subitizing slopes, a conclusion supported by a main effect of display type $\left[F(1,28)=904.41, M S_{\mathrm{e}}=1,594\right.$, $p<.01]$. Overall, slopes were greater for low spans than for high spans, an effect supported by a main effect of $\operatorname{span}\left[F(1,28)=11.99, M S_{\mathrm{e}}=2,154, p<.01\right]$. More importantly, this effect was moderated by a significant interaction between span and display type $[F(1,28)=$ $\left.12.87, M S_{\mathrm{e}}=1,594, p<.01\right]$. The interaction is depicted graphically in Figure 2. As can be clearly seen in Figure 2, there is virtually no difference between high- and low-span subject's subitizing slopes (21.49 and $25.99 \mathrm{msec}$ per bar, respectively). However, there is a significant difference between their reaction time slopes for counting trials $(294.51 \mathrm{msec}$ for high-span subjects, and $372.99 \mathrm{msec}$ for low-span subjects). Thus, as expected, the difference between high- and low-span subjects' reaction time slopes in the enumeration task occurred over the counting range, but not over the subitizing range.

The results from this experiment were very straightforward. High- and low-span subjects differed greatly in the enumeration task, but only to the extent that the enumeration task required controlled processing. On trials that required little or no controlled processing, high-and low-span subjects' reaction time slopes did not differ. However, when the need for controlled processing was introduced to the task, making subjects switch attention,

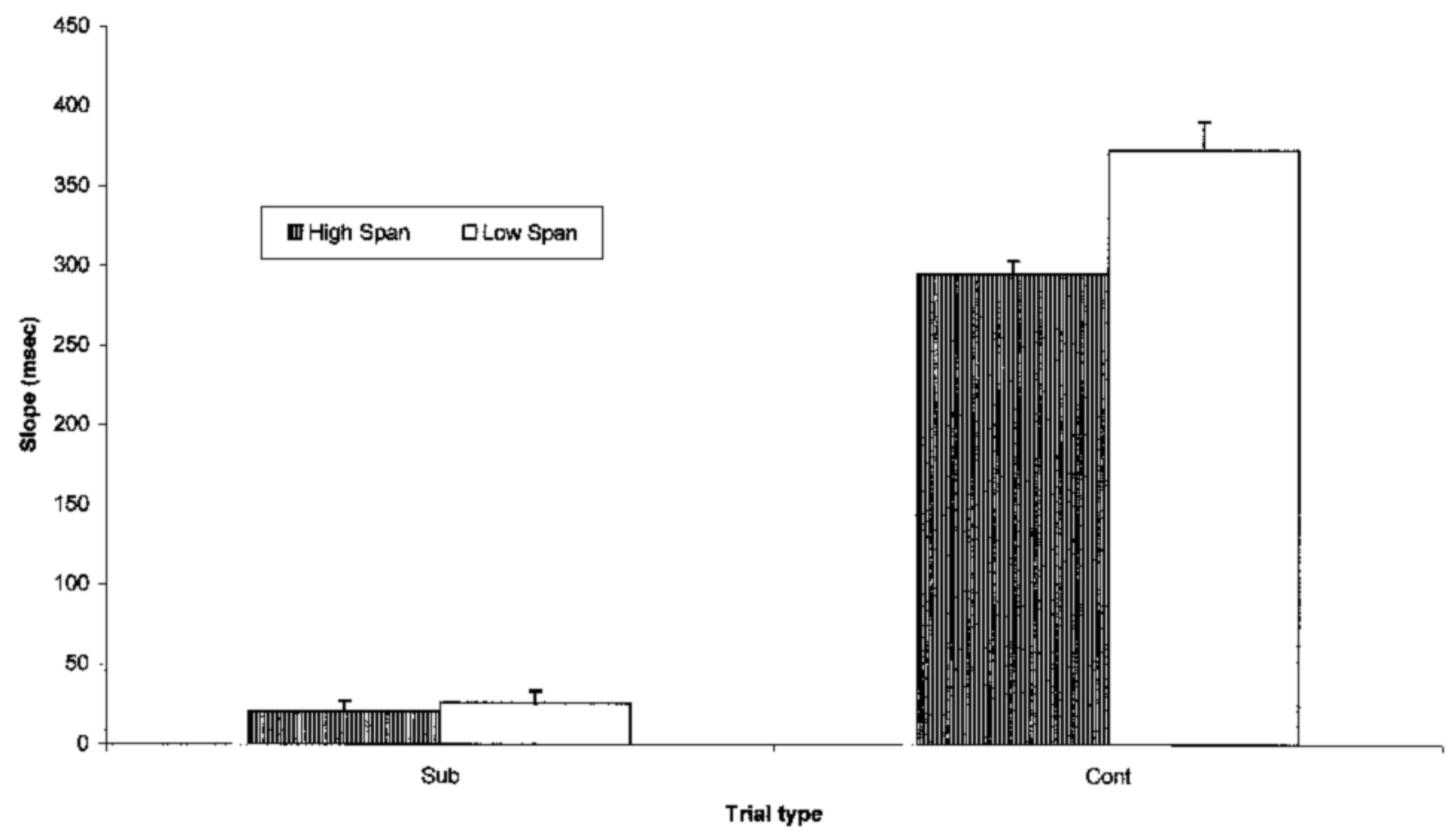

Figure 2. Experiment 1 slope differences for high- and low-span subjects. 
inhibiting returning to objects already counted, and keeping a running count of items, high- and low-span subjects' reaction time slopes differed by almost $80 \mathrm{msec}$. Thus, this first experiment demonstrated a lawful relationship between working memory capacity and controlled processing. The purpose of Experiment 2 was to extend these findings and demonstrate further the lawful relationship between working memory capacity and controlled processing.

Another interesting finding was that high- and lowspan subjects did not differ in the number of bars that they could subitize. This is particularly interesting because of the nature of the capacity limitations that are responsible for how many objects subjects can subitize versus how quickly they can count items in nonsubitizable displays. Our data do not disconfirm the existence of individual differences in a preattentive capacity limitation depending on FINSTS, but they do demonstrate that this kind of capacity limitation is qualitatively different from the kind that drive individual differences in working memory. The lack of difference between highand low-span subjects with regard to the number of bars that they subitized, coupled with the differences in reaction time slopes, converges on the notion that individual differences in working memory are the result of differences in effortful attentive processing.

\section{EXPERIMENT 2}

If the difference between high- and low-span subjects in Experiment 1 was due to differential ability to handle interfering information, adding distracting information to the visual display should affect high- and low-span subjects differently. We used two types of distractors in Experiment 2, conjunctive and disjunctive. A conjunctive distractor shared physical features (i.e., orientation or color) that subjects used to identify targets. Because of the physical similarity between to-be-counted items and to-be-ignored distractors that made distinguishing targets and distractors difficult, controlled processing was necessary for successful enumeration in this condition. Disjunctive distractors, on the other hand, shared only physical features (i.e., size and shape), which are not features that subjects could use to identify targets.

Previous research (Treisman, 1986; Treisman \& Gelade, 1980; Treisman \& Gormican, 1988; Treisman \& Sato, 1990; Wolfe, Cave, \& Franzel, 1989) has demonstrated that searching for single targets among conjunctive distractors is an effortful, attention demanding, serial process resulting in an increase in reaction time as a function of the number of conjunctive distractors in the display. Search for single targets among disjunctive distractors, on the other hand, occurs rapidly and without attention, resulting in the "pop-out" phenomenon. That is, increasing the number of disjunctive distractors in a visual search paradigm does not increase reaction time to identify targets, because searching for targets among dis- junctive distractors can be done with automatic parallel processing.

The addition of conjunctive and disjunctive distractors allowed for more predictions from a controlled processing view of working memory capacity. First, disjunctive distractors should have the same null effect on both highand low-span subjects, because the presence of disjunctive distractors does not require subjects to invoke additional controlled processing. On the other hand, because controlled processing is needed to overcome the interfering effects of the presence of conjunctive distractors, low spans should suffer from the presence of conjunctive distractors more than high spans. Moreover, this effect should increase as the number of conjunctive distractors increases, because increasing the number of conjunctive distractors increases the need for controlled processing to handle the increasing interference effects. Specifically, the reaction time cost, or how much longer it took subjects to enumerate objects because of the presence of distractors, should be negligible for both high- and lowspan subjects when the disjunctive distractors are present. However, the reaction time cost should be significant when conjunctive distractors are presented. More importantly, low spans should show a greater cost with each additional distractor in the conjunctive condition than would high spans.

Adding conjunctive distractors should also affect the processes involved in the enumeration task, so that counting one to three objects cannot be performed by using subitizing and hence will no longer be a strictly automatic process. That is, even when subjects are presented with one to three targets to enumerate among conjunctive distractors, the search for targets will be attention demanding, because subjects will need to use their attention to effortfully and serially search each display for targets (Trick \& Pylyshyn, 1993). Thus, in the conjunctive condition, the measure of automatic processing used in Experiment 1 (subitizing slope) will no longer be a pure measure of automatic processing. In fact, subjects were not expected to subitize in the conjunctive condition, because of the additional attentional requirements, and as such, "subitizing slope" is somewhat a misnomer. However, to be consistent with Experiment 1,we will retain "subitizing slope" to refer to the reaction time slope for target display sizes $1-3$.

\section{Method}

Subjects. Thirty undergraduates from the University of South Carolina Department of Psychology Human Subject Pool were recruited for this experiment. None of these subjects participated in Experiment 1.

Apparatus. This was the same as in Experiment 1.

OSPAN. This was the same as in Experiment 1.

Enumeration. On each trial, subjects were presented with 1-12 vertical yellow bars on a black background. Unlike in Experiment 1, however, distractors were present on $80 \%$ of the displays. In the conjunctive condition, yellow vertical bars (targets) were presented along with white vertical and yellow horizontal bars (distractors). In the disjunctive condition, yellow vertical (targets) were presented 
along with white horizontal (distractors). Distractor type (conjunctive or disjunctive) was a blocked, within-subjects variable. Half of the subjects enumerated in the conjunctive condition first, and half enumerated in the disjunctive condition first. On any given trial, enumeration occurred with $0,2,4,8$ or 16 distractors. The display matrix covered an area of approximately $4.0^{\circ} \times 6.0^{\circ}$ of visual angle. Before each trial, a get ready signal $(*)$ appeared for $500 \mathrm{msec}$ in the center of the target matrix, followed by a blank screen for $50 \mathrm{msec}$ and then the enumeration display, which remained on the screen until the subject provided a vocal response. Reaction time was taken from the onset of the enumeration display until the subject responded orally with the number of objects. Following the subject's response, the experimenter keyed in the response to record accuracy.

In each distractor condition (conjunctive and disjunctive), subjects performed 15 trials of each target display size, resulting in 180 trials per distractor condition, or 360 trials per subject. For both distractor conditions, the subjects performed 30 trials of each distractor size. The subjects performed 12 practice trials before performing six blocks of 60 trials.

\section{Results and Discussion}

The high-span subjects' $(n=15)$ mean OSPAN score was $26.96(S D=4.40)$, and the low-span subjects' $(n=$ $15)$ mean OSPAN score was $6.86(S D=2.80)$.

As in Experiment 1, overall accuracy on the enumeration task was very high $(95.4 \%$ and $94.3 \%$ for high and low spans, respectively), indicating that subjects performed the enumeration task as quickly as possible without sacrificing accuracy. Further, the linear fit (as indicated by $R^{2}$ values) of the reaction time slopes for highand low-capacity subjects across display type ranged from .67 to .83 .

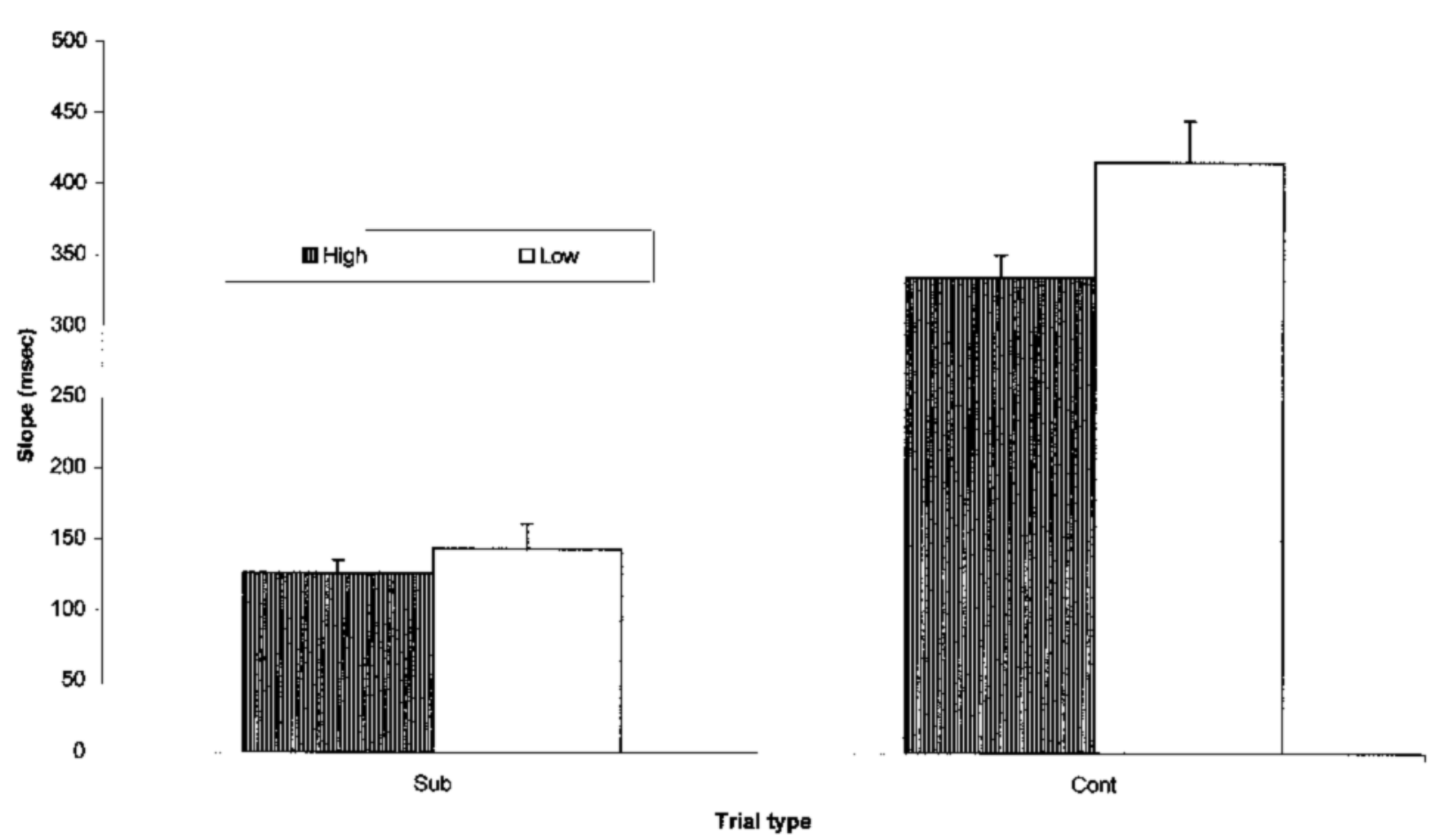

Trial type

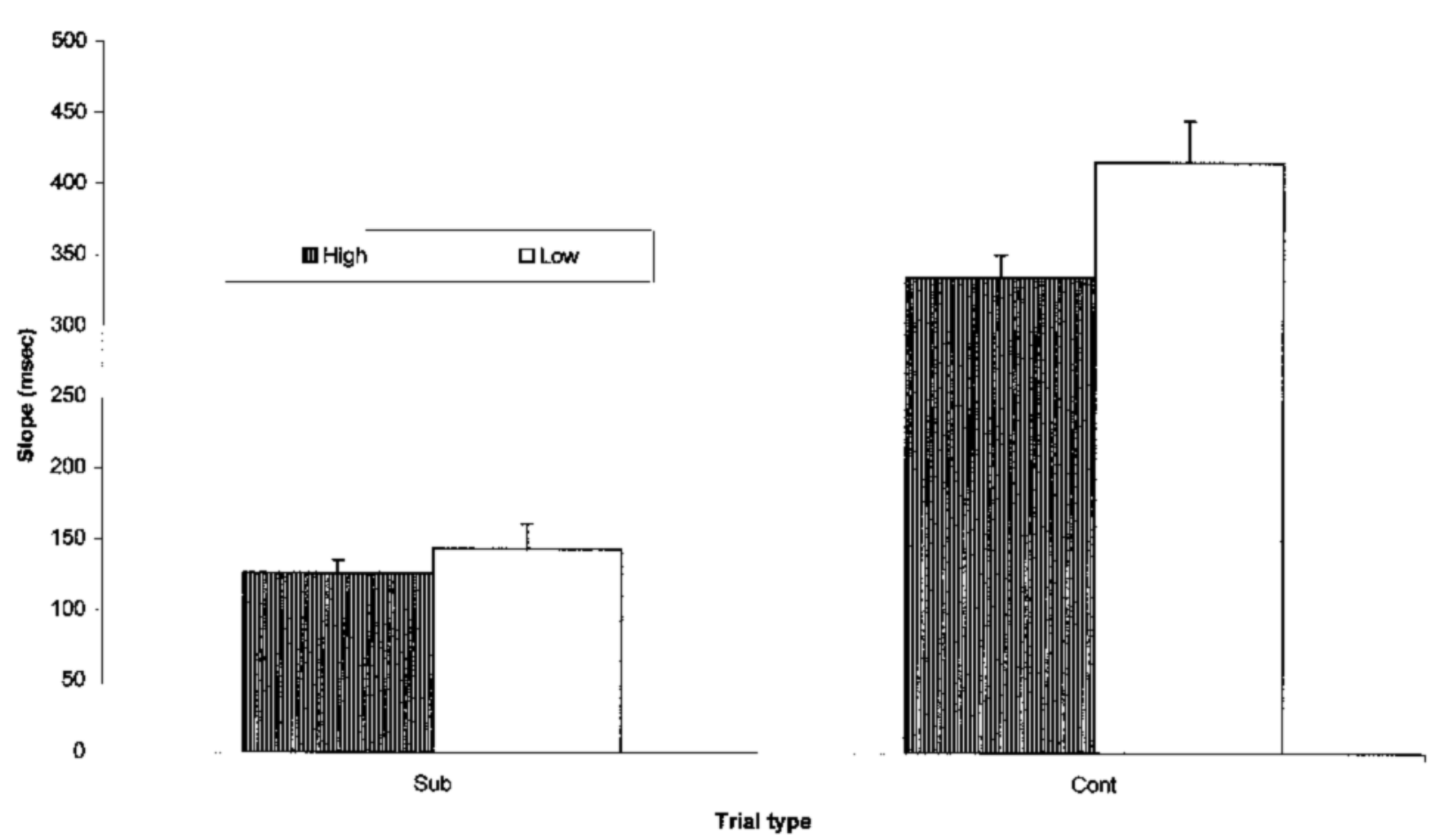

Figure 3. Reaction time slope differences for high- and low-span subjects, Experiment 2.
Low spans' reaction time slopes were slower than high spans', indicated by a main effect of $\operatorname{span}[F(1,28)=5.33$, $\left.M S_{\mathrm{e}}=6,724, p<.03\right]$, and reaction time slopes were greater for counting than for subitizing trials $[F(1,28)=$ $\left.177.38, M S_{\mathrm{e}}=4,905, p<.01\right]$. Moreover, there was a marginal interaction between span and display size $\left[F(1,28)=3.22, M S_{\mathrm{e}}=4,905, p<.07\right]$. Planned comparisons indicated that the $17-\mathrm{msec}$ difference in subitizing slopes between high and low spans was not significant $[t(29)=1.31, p>.05]$, whereas the 79-msec difference in counting slopes was significant $[t(29)=2.84, p<.05]$. These data are depicted in Figure 3.

The differential effect of distractor type was also evident in the significant interaction between span, distractor type and number of distractors $(0,2,4,8$, or 16) $\left[F(4,112)=3.90, M S_{\mathrm{e}}=6,981, p<.05\right]$. This interaction is depicted in Figure 4. This interaction indicated that the adverse effect of conjunctive distractors was greatest for low spans when the task required counting processes. Neither the four-way interaction nor any of

To further demonstrate the adverse effect that conjunctive distractors had on low spans, we examined the reaction time cost associated with each distractor. That is, how much more time did it take high-and low-capacity subjects to respond for each conjunctive or disjunctive distractor on a given display? To estimate reaction time costs for each subject, the reaction time slopes associated with the number of conjunctive and disjunctive distractors were estimated. Consistent with our predictions, the remaining three-way interactions was significant. 


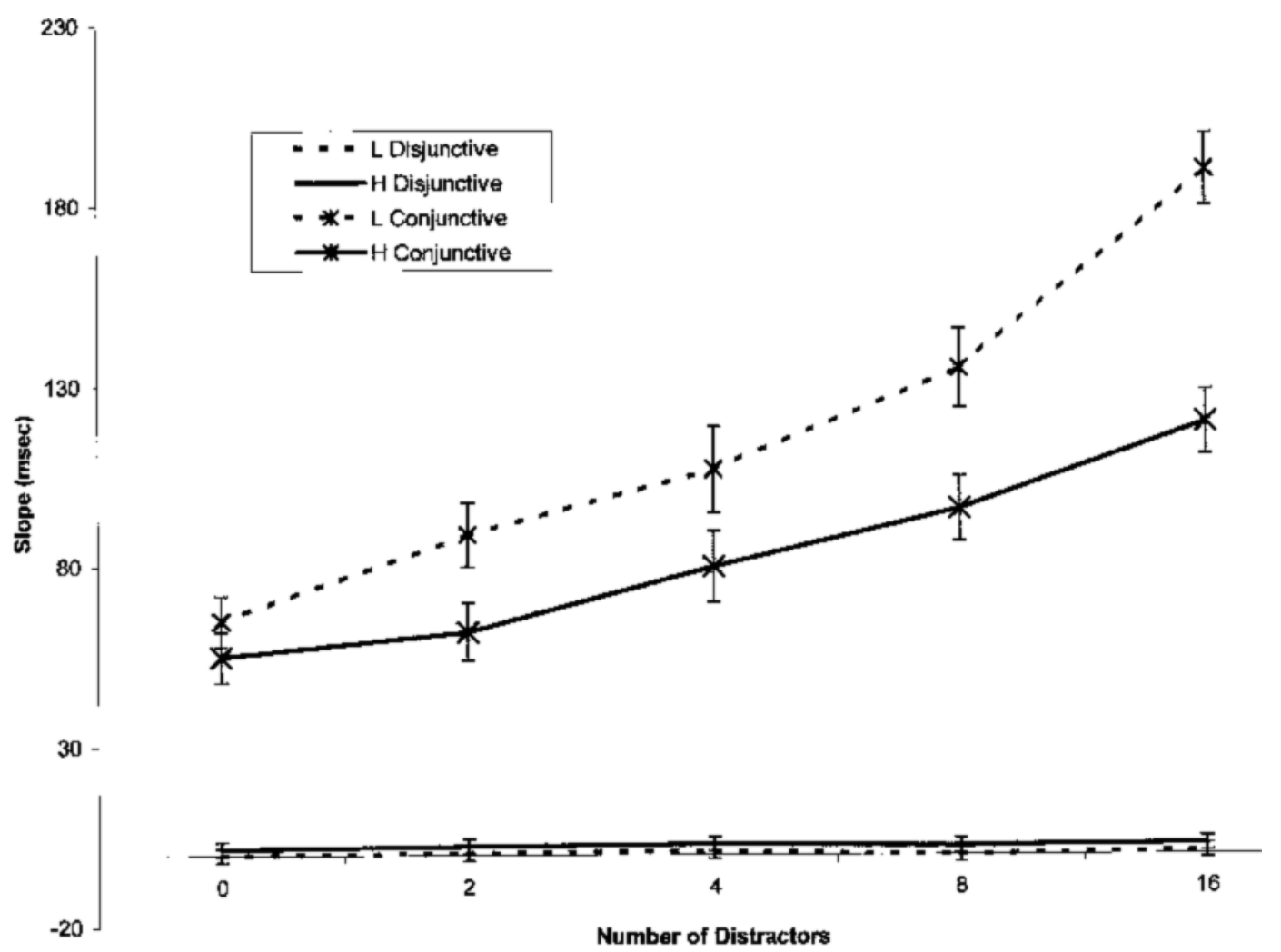

Figure 4. Span $\times$ distractor type $\times$ number of distractors interaction, Experiment 2 .

high- and low-span subjects showed minimal counting time costs with disjunctive distractors $(2.55$ and $.58 \mathrm{msec}$ per distractor, respectively). That is, for each additional disjunctive distractor, high- and low-span subjects added only a few milliseconds to their reaction times. As predicted, both groups showed greater costs with conjunctive distractors, and the effect was much more profound for the low spans (high-span reaction time cost $=$ $86 \mathrm{msec}$; low-span reaction time cost $=114 \mathrm{msec}$ ). These findings were supported by a significant interaction between span and distractor type for reaction time cost $\left[F(1,28)=7.01, M S_{\mathrm{e}}=482, p<.02\right]$.

\section{GENERAL DISCUSSION}

The motivation for the present study derives from recent research demonstrating the conditions in which subjects with differences in working memory capacity have concomitant differences in task performance (e.g., Cantor \& Engle, 1993; Conway \& Engle, 1994; Daneman \& Carpenter 1980; Rosen \& Engle, 1997). In the experiments presented here, high- and low-capacity subjects performed a simple counting task under varying attentional conditions. The important message from our data is that only under conditions requiring controlled processing in the face of distracting information did capacity differences arise. This is compelling evidence that working memory capacity is limited by controlled processing. Before discussing this notion further, we will address a possible alternative explanation for our data.

One alternative explanation of our results could be that the differences between high- and low-span subjects lies in speed of processing rather than some aspect of controlled processing capability (Verhaeghen \& Salthouse, 1998). A processing speed account may argue that the lack of difference between high- and low-span subjects on subitizing trials is due to a lack of power, or that subjects' performance on these trials is at the floor. In fact, given the present data, a processing speed account may make several of the same predictions that we do. However, a controlled attention account clearly predicts individual differences on conjunctive but not disjunctive trials and on counting but not subitizing trials a priori because efficient target searches require controlled attention to inhibit distractors and guide visual search (Treisman \& Sato, 1990).Thus, increased controlled processing capacity leads to faster, more efficient searches. Although a processing theory may make these "predictions," it cannot do so without invoking assumptions such as differential speed effects for different distractors, and floor performance on subitizing trials.

One limitation of the present work is that we did not include a traditional processing speed measure in this study. Had we done so, we would be able to assess more 
directly the role of individual differences in processing speed, and how those differences contributed to our observed enumeration differences. However, recent work by Conway, Cowan, Bunting, Therriault, and Minkoff (2000) has demonstrated that processing speed does not account for the relationship between working memory and fluid intelligence. In that study, subjects performed several working memory, processing speed, and fluid intelligence tasks. Latent variable analyses strongly suggested that the relationship between working memory and fluid intelligence was not affected by processing speed, despite processing speed's strong relationship with working memory. Thus, although processing speed is related to working memory and other higher order cognitive functions, it does not control the relationships.

Why do high-span subjects outperform low-span subjects only on counting and conjunctive trials? To answer this question best, we should consider what processes are involved in each kind of trial. The most important difference between the trials is that subitizing is a preattentive process, and counting requires a number of attentiondemanding steps, including indexing items, switching attention from item to item, summing the number of items, and maintaining a running total of the items. This series of steps will be performed more efficiently if the subject inhibits re-counting already counted items. Given the wealth of data demonstrating that high-span subjects are better inhibitors and can handle interfering information better than low-span subjects, we argue that their efficiency in the counting task is a by-product of a more efficient inhibitory ability/process. This explanation is consistent with the observed individual differences on counting trials, but not on subitizing trials as well.

Our data present supporting evidence for a theory of working memory capacity developed over the past few years and voiced most recently by Engle, Kane, and Tuholski (1999). In this theory, working memory is a system similar to that described by Cowan $(1988,1995)$. It consists of a short-term memory component, of long-term memory traces activated above a critical threshold, a central executive, and other skills and strategies used for maintaining activation. Finally, we suggest - and the data presented here support this suggestion - that individual differences in working memory capacity are due to individual differences in controlled processing capability.

\section{REFERENCES}

BADDELEy, A. D. (1986). Working memory. New York: Oxford University Press.

BadDeley, A. D., \& Hitch, G. J. (1974). Working memory. In G. H. Bower (Ed.), The psychology of learning and motivation (Vol. 8, pp. 47-90). New York: Academic Press.

CAntor, J., \& ENGLE, R. W. (1993). Working memory capacity as longterm memory activation: An individual differences approach. Journal of Experimental Psychology: Learning, Memory, \& Cognition, 5, 1101-1114

CHI, M. T. H., \& KLAHR, D. (1975). Span and rate of apprehension in children and adults. Journal of Experimental Child Psychology, 19, 434-439.

Conway, A. R. A., Cowan, N., Bunting, M. F., Therriault, D., \& MinKofF, S. (2000). A latent variable analysis of working memory capacity, short term memory capacity, processing speed, and general fluid intelligence. Manuscript submitted for publication.

Conway, A. R. A., \& Engle, R. W. (1994). Working memory and retrieval: A resource-dependent inhibition model. Journal of Experimental Psychology: General, 123, 354-373.

Conway, A. R. A., Tuholski, S. W., Shisler, R. J., \& Engle, R. W. (1999). The effect of memory load on negative priming: An individual differences investigation. Memory \& Cognition, 27, 1042-1050.

CowAn, N. (1988). Evolving conceptions of memory storage, selective attention, and their mutual constraints within the human information processing system. Psychological Bulletin, 104, 163-191.

CowAn, N. (1995). Attention and memory: An integrated framework. New York: Oxford University Press.

Daneman, M., \& Carpenter, P. (1980). Individual differences in working memory and reading. Journal of Verbal Learning \& Verbal Behavior, 19, 450-466.

Engle, R. W., KAne, M., \& Tuholski, S. W. (1999). Individual differences in working memory capacity and what they tell us about controlled attention, general fluid intelligence, and functions of the prefrontal cortex. In A. Miyake \& P. Shah (Eds.), Models of working memory: Mechanisms of active maintenance and executive control (pp. 102-134), Cambridge: Cambridge University Press.

Engle, R. W., Tuholski, S. W., Laughlin, J. E., \& Conway, A. R. A. (1999). Working memory, short-term memory, and general fluid intelligence: A latent-variable approach. Journal of Experimental Psychology: General, 128, 309-331.

ERICSSON, K. A., \& Dulaney, P. F. (1999). Long-term working memory as an alternative to capacity models of working memory in everyday skilled performance. In A. Miyake \& P. Shah (Eds.), Models of working memory: Mechanisms of active maintenance and executive control (pp. 257-297). Cambridge: Cambridge University Press.

ERICSSON, K. A., \& KinTSCH, W. (1995). Long-term working memory. Psychological Review, 102, 211-245.

Jevons, W. (1871). The power of numerical discrimination. Nature, $\mathbf{3}$, 281-282.

KANE, M. J., \& ENGLE, R. W. (2000). Working memory capacity, proactive interference, and divided attention: Limits on long-term memory retrieval. Journal of Experimental Psychology: Learning, Memory, \& Cognition, 26, 336-358.

KING, J., \& JUST, M. A. (1991). Individual differences in syntactic processing: The role of working memory. Journal of Memory \& Language, 30, 580-602.

Kyllonen, P. C., \& Chrystal, R. E. (1990). Reasoning ability is (little more than) working memory capacity? Intelligence, 14, 389-433.

MacDonald, M. C., Just, M. A., \& CARPenter, P. A. (1992). Working memory constraints on the processing of syntactic ambiguity. $\mathrm{Cog}$ nitive Psychology, 24, 56-98.

MiyaKe, A., \& SHAH, P. (EDS.) (1999). Models of working memory: Mechanisms of active maintenance and control. Cambridge: Cambridge University Press.

Pylyshyn, Z. (1994). Some primitive mechanisms of spatial attention. Cognition, 50, 363-384.

Rosen, V. M., \& ENGLE, R. W. (1997). The role of working memory capacity in retrieval. Journal of Experimental Psychology: General, 126, 211-227.

Rosen, V. M., \& ENGLE, R. W. (1998). Working memory capacity and suppression. Journal of Memory \& Language, 39, 418-436.

Treisman, A. [M.] (1986). Properties, parts, and objects. In K. R. Boff, L. Kaufman, \& J. P. Thomas (Eds.), Handbook of perception and human performance: Vol. 2. Cognitive processes \& performance (pp. 1-70). New York: Wiley.

Treisman, A. M., \& Gelade, G. (1980). A feature-integration theory of attention. Cognitive Psychology, 12, 97-136.

Treisman, A. [M.], \& Gormican, S. (1988). Feature analysis in early vision: Evidence from search asymmetries. Psychological Review, 95, 15-48.

Treisman, A. [M.], \& Sato, S. (1990). Conjunction search revisited. Journal of Experimental Psychology: Human Perception \& Performance, 16, 459-478.

Trick, L. M. \& Pylyshyn, Z. W. (1993). What enumeration studies can show us about spatial attention: Evidence for limited capacity preat- 
tentive processing. Journal of Experimental Psychology: Human Perception \& Performance, 19, 331-351.

Trick, L. M., \& Pylyshyn, Z W. (1994). Why are small and large numbers enumerated differently? A limited-capacity preattentive stage in vision. Psychological Review, 101, 80-102.

Turner, M. L., \& Engle, R. W. (1989). Is working memory capacity task dependent? Journal of Memory \& Language, 28, 127-154.
Verhaeghen, P., \& Salthouse, T. A. (1998). Meta-analysis of age-cognition relations in adulthood: Estimates of linear and nonlinear age effects. Psychological Bulletin, 122, 231-249.

Wolfe, J. M., Cave, K. R., \& Franzel, S. L. (1989). Guided search: An alternative to the feature integ ration model for visual search. Journal of Experimental Psychology: Human Perception \& Performance, 15, 419-433.

(Manuscript received August 9, 1999;

revision accepted for publication September 8, 2000.) 